\title{
CDKN2A NP_000068.1:p.A147T
}

National Cancer Institute

\section{Source}

National Cancer Institute. CDKN2A NP 000068.1:p.A147T. NCI Thesaurus. Code C146948.

A change in the amino acid residue at position 147 in the cyclin-dependent kinase inhibitor 2 protein where alanine has been replaced by threonine. 